\title{
Citizenship Activity: Role of Social Media
}

\section{Гражданская активность: роль социальных медиа}

\section{Iryna Bondarevska}

Ph.D. in Psychology, Assistant Professor, Senior Researcher, Laboratory of Psychology of Mass Communication and Media Education, Institute of Social and Political Psychology of NAES of Ukraine, Kyiv (Ukraine)

ORCID ID: https://orcid.org/0000-0002-7006-0979

E-mail: bondarevskaya@ua.fm

\section{Ирина Бондаревская}

Кандидат психологических наук, доцент, старший научный сотрудник лаборатории психологии массовой коммуникации и медиаобразования, Институт социальной и политической психологии НАПН Украины, г. Киев (Украина)

\section{Viktoriia Mykhailenko}

Ph.D. in Psychology, Assistant Professor, Department of Social and Humanitarian Training of Odessa State Academy of Technical Regulation and Quality, Odesa (Ukraine)

ORCID ID: https://orcid.org/0000-0003-2584-5571

E-mail: mykhaylenkova@ukr.net

\section{Виктория Михайленко}

Кандидат психологических наук, доцент, доцент кафедры общественно-гуманитарной подготовки, Одесская государственная академия технического регулирования и качества, г. Одесса (Украина)

The author's contribution: I. Bondarevska - 70\%, V. Mykhailenko-30\%. Авторський внесок: И. Бондаревская - 70\%, В. Михайленко - 30\%.

Address for correspondence, e-mail: kpnu_lab_ps@ukr.net Copyright: (C) Bondarevska Iryna, Mykhailenko Viktoriia

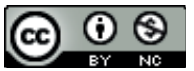
The article is licensed under CC BY-NC 4.0 International (https://creativecommons.org/licenses/by-nc/4.0/)

(C) Bondarevska Iryna, Mykhailenko Viktoriia

DOI (article): https://doi.org/10.32626/2227-6246.2019-46.40-58 http://journals.uran.ua/index.php/2227-6246 


\section{ABSTRACT}

The article presents theoretical approaches to citizenship activity as well as typology of citizenship activity developed by B. Krzywosz-Rynkiewicz and A. Zalewska. The role of social media in development and spread of citizenship activity is considered. The tasks of the article: 1) theoretical review of research works in the field of citizenship activity and role of social media in development and spread of citizenship activity; 2) analysis of youth's citizenship activity empirical research results. For the sake of studying peculiarities of adolescents' citizenship activity the empirical research was conducted in Kryvyi Rih and Sofiivka using Citizenship Behavior Questionnaire as method of research. Each of three scales (passive, semi-active and active citizenship behavior) contains sub-scales: active citizenship behavior - political citizenship, active citizenship for change, active social citizenship, active personal citizenship; semi-active citizenship: respecting laws and rules, voting, working for common good and honest job; passive citizenship: national identity and patriotism. 371 respondents participated in the research. Results of the research showed high passive and semi-active citizenship activity and low active citizenship activity telling us about presence of potential but unwillingness for active changes. It is shown that in Ukraine unlike other countries where the research using this method has been conducted there is no statistically significant gender differences in passive, semiactive and active citizenship behavior. At the same time statistically significant differences were revealed between youth living in a city and in village as well as some statistically significant differences depending on age. It was concluded that citizenship activity as possibility to influence on political processes and decisions could be considered as one of the mechanisms of trust in government and state institutions regulation among citizens. Importance of fake news recognition skills is underlined as well as importance of media literacy because in the periods of social, political and economic uncertainty it is especially difficult to distinguish between fake and reliable information.

Key words: citizenship activity, types of citizenship activity, citizenship activity of adolescents, social media, protests.

\section{Вступление}

В современной социально-политической реальности социальные медиа выполняют множество модерирующих функций, поскольку доступ к ним происходит через смартфон, который у большинства граждан всегда с собой. Через

(c) Bondarevska Iryna, Mykhailenko Viktoriia DOI (article): https://doi.org/10.32626/2227-6246.2019-46.40-58 
социальные медиа новости мгновенно облетают мир, и через те же социальные медиа можно верифицировать новости у очевидцев. В революционные периоды через социальные медиа открыт доступ к стримам с мест событий практически без политической цензуры, свойственной телевидению. Гражданская активность в значительной степени подпитывается новостями и эмоциями, циркулирующими в социальных медиа. Рассмотрим подходы к изучению гражданской активности.

3. Мелосик (Melosik, 1998) отмечает, что гражданственность является неоднозначным и контекстуальным концептом, который тесно связан с культурными и историческими детерминантами. Во время войны определение гражданственности пропитано патриотизмом и похоже на гражданина-солдата, в период послевоенного восстановления оно приближается к гражданину-строителю, во времена бедствий оно ближе к концепции гражданина-спасателя, который помогает нуждающимся, во время серьезных реформ - к гражданину-реформатору, а в период мира и стабильности - к гражданину-работнику.

Дж. Хербст (Herbst, 2005) предложил четыре модели гражданского общества на основе параметров индивидуализма / коллективизма и автономии. Автономия определяет силу связей между гражданским обществом и институтами. Индивидуализм / коллективизм относятся к таким основам гражданственности, как ценности личности и коллективные ценности, которые уважает всё общество. Классическая модель гражданственности связана с ценностями личности и высоким уровнем автономии. В этой модели индивиды характеризуются высоким уровнем гражданской осознанности, они придерживаются универсальных ценностей, уважают закон и голосуют на выборах. Они уважают социальные нормы и интересуются общественными делами. Мобилизационная лодель соотносится с ценностями личности и определяет отношения между различными сферами социальной реальнос(c) Bondarevska Iryna, Mykhailenko Viktoriia

DOI (article): https://doi.org/10.32626/2227-6246.2019-46.40-58 http://journals.uran.ua/index.php/2227-6246 
ти. В этой модели индивиды рациональны и предприимчивы, они создают социальный капитал и берут дела в свои руки. Их гражданские аттитюды отражаются, в основном, в экономической активности и взаимопомощи как части системы социальной поддержки. Ассоциативная модель основывается на коллективных ценностях и характеризуется высоким уровнем автономии. Эта модель уравновешивает всемогущество государства. Граждане больше вовлечены в негосударственные организации и ассоциации. Гражданская активность проходит за пределами государственных структур. Граждане проводят мониторинг действий правительства, инициируют протесты и определяют направление изменений. Модель сообществ также основывается на коллективных ценностях, но соотносится с социальными связями. Ее можно применить к маленьким и интегрированным территориальным сообществам с сильными связями между членами сообществ. В этой модели граждане поддерживают социальные связи, групповую идентичность и существующий порядок. Они представляют сообщество в государственных организациях, например, в качестве политических партий, а также принимают участие в проектах, инициируемых местными властями.

Э. Тэйсc-Mopc (Theiss-Morse, 1993) в результате исследования роли гражданственности в современном обществе выделила четыре типа граждан в зависимости от аттитюдов и уровня гражданской вовлеченности. Пассивный и не вовлеченный гражданин - это отчужденный гражданин, который не проявляет интерес к общественным событиям и политике. Такой гражданин отдает судьбу нации и общества в руки правительства, принимает решения правительства, но не интересуется тем, как функционируют власти и что они делают. Полуактивный голосующий гражданин интересуется политикой и общественными событиями, ищет важную информацию и старается понять локальные события. Он / она осознанно выбирает кандидатов на выборах, но лично не вовлечен в политику и социальную активность. Актив-

(C) Bondarevska Iryna, Mykhailenko Viktoriia DOI (article): https://doi.org/10.32626/2227-6246.2019-46.40-58 
DOI: https://doi.org/10.32626/2227-6246.2019-46 2019. Випуск 46

ный гражданин - социальный активист и бунтарь, который не доверяет властям и политическим лидерам, мониторит действия правительства и активно лоббирует защиту гражданских прав. Он / она является членом протестного движения, способствующего изменениям. Активный гражданинпредставитель - это активист, который работает от имени государства. Он / она представляет интересы специфических групп, организаций и институтов и лоббирует решения, которые улучшают их условия жизни и деятельности.

M. Левицка (Lewicka, 2004) выделяет три типа гражданского участия: 1) протест, участие в демонстрациях, выражение недовольства при помощи сбора подписей под петициями; 2) конструктивные действия от имени местного сообщества, жилого комплекса или места работы; 3) общее гражданское участие, включающее как протесты, так и конструктивные действия. При этом М. Левицка отмечает, что граждане, вовлеченные в конструктивные действия, характеризуются высоким уровнем социальных ресурсов, проявляемых, например, в добрососедских отношениях и приверженности к месту проживания. Граждане, вовлеченные в общее гражданское участие, демонстрируют высокий уровень интеллектуальных ресурсов, которые проявляются в образовании, широте интересов и меньшей эмоциональной связи с местом проживания. Таким образом, М. Левицка определяет два направления по пути к гражданскому участию: эмоциональный / социальный и интеллектуальный, которые активируются разными условиями (Lewicka, 2004).

Дж. Торней-Пурта, С. Х. Барбер и В. К. Ричардсон (Torney-Purta, Barber \& Richardson, 2004) на основании исследования, проведенного в 28 странах на 90000 респондентах, показывают связь между всеми типами гражданского поведения и уровнем доверия по отношению к сообществу, друзьям, знакомым и семье. Авторы выделяют традиционное политическое участие и участие в жизни сообщества. Традиционное политическое участие связано с государствен(c) Bondarevska Iryna, Mykhailenko Viktoriia

DOI (article): https://doi.org/10.32626/2227-6246.2019-46.40-58 
DOI: https://doi.org/10.32626/2227-6246.2019-46

ной политической структурой, интересом к общественной жизни, национальной истории и системам управления и готовностью принимать участие в выборах. Участие в жизни сообщества подразумевает участие в акциях протеста, волонтерство, работу в организациях по правам человека и защите окружающей среды.

Среди моделей гражданской активности хотелось бы подробно остановиться на модели, разработанной Б. КшивошРынкевич и А. Залевской (Zalewska \& Krzywosz-Rynkiewicz, 2011; Krzywosz-Rynkiewicz \& Zalewska, 2015), поскольку авторы также разработали Опросник гражданского поведения (две версии - для школьников и для студентов), который был адаптирован на украинский язык И. Бондаревской и К. Бондар (Bondarevskaya, Krzywosz-Rynkiewicz \& Bondar, 2017).

Б. Кшивош-Рынкевич и А. Залевска (Zalewska \& KrzywoszRynkiewicz, 2011; Krzywosz-Rynkiewicz \& Zalewska, 2015) выделяют 6 типов гражданского поведения:

- пассивное гражданское поведение - включает поведение, выражающее национальную идентичность, чувство принадлежности к государству или нации, уважение к национальным символам и патриотизм;

- полуактивное гражданское поведение - выражается в преданности государству и государственным институтам, а также в участии в выборах (голосовании);

- активное социальное гражданское поведение - выражается в волонтерской работе на пользу местного сообщества и окружающей среды, представлении местного сообщества и решении местных проблем;

- активное политическое гражданское поведение включает желание принимать участие в управлении, вступив в политическую партию;

- активное, направленное на изленения гражданское поведение - проявляется в попытках мониторинга действий правительства, законных и незаконных протестах;

(c) Bondarevska Iryna, Mykhailenko Viktoriia DOI (article): https://doi.org/10.32626/2227-6246.2019-46.40-58 
- активное личностно ориентированное гражданское поведение - направлено на личностное развитие, независимость, финансовую стабильность и предпринимательство.

Модель гражданского поведения Б. Кшивош-Рынкевич и А. Залевской (Zalewska \& Krzywosz-Rynkiewicz, 2011; Krzywosz-Rynkiewicz \& Zalewska, 2015) основана на том, что индивидуальные ресурсы могут как способствовать гражданской активности в ее политических, социальных и личностных проявлениях, так и предотвращать получение значимого опыта.

Б. Кшивош-Рынкевич и А. Залевска (Krzywosz-Rynkiewicz \& Zalewska, 2015) проанализировали индивидуальные ресурсы на двух уровнях: 1) базовых и 2) специфических характеристиках личности. Базовые характеристики сильнее определены биологическими факторами и включают темперамент и черты личности, определяемые моделью Большой пятерки. Специфические характеристики личности (ценности, тип оптимизма, локус контроля, ответственность, психологическая стойкость) более подвержены влиянию факторов среды и культуры, включая мотивационные и социальнокогнитивные конструкты относительно себя, других, мира и будущего, в соответствии с социально-когнитивной теорией личности.

\section{Задачи статьи}

1. Теоретический обзор исследований гражданской активности и роли социальных медиа в развитии и распространении гражданской активности.

2. Анализ результатов эмпирического исследования гражданской активности молодежи.

\section{Результаты и дискуссии}

При рассмотрении гражданского поведения Б. КшивошРынкевич и А. Залевска (Krzywosz-Rynkiewicz \& Zalewska, 2015 ) особенное внимание уделяют влиянию на гражданское (c) Bondarevska Iryna, Mykhailenko Viktoriia

DOI (article): https://doi.org/10.32626/2227-6246.2019-46.40-58 
поведение следующих факторов: личностных характеристик, возраста и места проживания (большой город, поселок городского типа или деревня). Базовые черты личности менее связаны с гражданским участием, но добросовестность связана с интенсивностью проявления гражданского участия. Специфические характеристики личности с большей вероятностью влияют на гражданское поведение, чем базовые. Конструкты, поддерживающие достижение целей, такие как социальный оптимизм (вера в то, что члены сообщества могут эффективно решать местные проблемы), индивидуальная ответственность и вовлеченность, являются ресурсами преодоления пассивного гражданского поведения. Уровень социальной ориентации влияет на поведение, направленное на увеличение надперсональных выгод, которые являются элементами полуактивного гражданского поведения и просоциальных аттитюдов.

Б. Кшивош-Рынкевич и А. Залевска (Krzywosz-Rynkiewicz \& Zalewska, 2015) отмечают, что с возрастом черты личности становятся более тесно связаны с гражданским участием. В позднем подростковом возрасте базовые черты личности с большей вероятностью определяют гражданское участие, чем специфические черты. Черты, предотвращающие гражданскую пассивность, больше проявляются в больших городах. Можно предположить, что маленькие сообщества с ограниченными возможностями социальных контактов способствуют поведению, основанному на взаимопомощи и сотрудничестве (Eliasz, 2002). В больших городах гражданское участие определяется скорее индивидуальными ресурсами.

В 2017 г. на украинской выборке в Кривом Роге (643 618 жителей) и пгт Софиевке (8243 жителя) было проведено исследование гражданского поведения молодежи в соответствии с моделью гражданского поведения Б. Кшивош-Рынкевич и А. Залевской (Krzywosz-Rynkiewicz \& Zalewska, 2015). В исследовании принял участие 371 респондент - 185 человек из Кривого Рога и 186 из Софиевки, 183 девушки и 188 юношей в возрасте 11 (121 человек), 14 (128 человек) и 17-18 (122

(c) Bondarevska Iryna, Mykhailenko Viktoriia DOI (article): https://doi.org/10.32626/2227-6246.2019-46.40-58 
человека) лет. Главной целью исследования было изучение гражданского поведения молодых людей, родившихся после 1991 г. С одной стороны, они были свидетелями того, как Украина стала независимым государством, что способствовало развитию патриотизма и национальной идентичности. С другой стороны, они прочувствовали на себе экономические, политические и социальные изменения, которые дестабилизировали их повседневную жизнь.

Исследование проводилось при помощи Опросника гражданского поведения (Zalewska \& Krzywosz-Rynkiewicz, 2011). Данный опросник состоит из 34 вопросов, измеряемых по 4-бальной шкале. Каждая из трех шкал (активное, полуактивное и пассивное гражданское поведение) содержит субшкалы: активное гражданское поведение - «политическая активность», «активность ради изменений», «социальная активность», «личная активность»; полуактивное гражданское поведение - «законопослушность», «голосование», «общественное благо» и «честная работа»; пассивное гражданское поведение - «национальная идентичность» и «патриотизм». Кроме Украины, исследования гражданского поведения по Опроснику гражданского поведения проводились еще в 15 странах. Рассмотрим результаты, полученные на украинской выборке.

Наиболее высокими показатели оказались по следующим субшкалам: «национальная идентичность» $(\mathrm{M}=3,45$; $\mathrm{SD}=0,46)$, «законопослушность» $(\mathrm{M}=3,38 ; \mathrm{SD}=0,51)$, «гражданская сила» $(\mathrm{M}=3,28$; $\mathrm{SD}=0,56)$, «личная активность» $(\mathrm{M}=3,30 ; \mathrm{SD}=0,48)$. Высокие баллы по шкале национальной идентичности среди молодежи могут быть результатом политических событий, национально-патриотического воспитания и войны на Востоке Украины. Следует отметить, что самые низкие баллы были получены по вопросу об интересе к истории Украины. Исключение этого вопроса повышает коэффициент $\alpha$-Кронбаха. Это говорит о том, что национальная идентичность в Украине на данный момент не (c) Bondarevska Iryna, Mykhailenko Viktoriia

DOI (article): https://doi.org/10.32626/2227-6246.2019-46.40-58 
связана с интересом к истории государства. В целом, баллы по пассивному гражданскому поведению достаточно высокие $(\mathrm{M}=3,15 ; \mathrm{SD}=0,45)$.

Хотя полуактивное гражданское поведение сравнительно высокое $(\mathrm{M}=3,33$; $\mathrm{SD}=0,43)$, вопрос о будущем голосовании на выборах показывает, что молодые украинцы скорее будут голосовать, чем нет. Таким образом, важность голосования не настолько высока, как должна была бы быть, и вопросы, связанные с голосованием, необходимо включать в программы гражданского образования.

«Законопослушность» среди молодежи достаточно высокая $(\mathrm{M}=3,38 ; \mathrm{SD}=0,51)$, что демонстрирует позитивное отношение к уважению государственных институтов, законов и норм. Баллы по субшкале «гражданская сила» также достаточно высокие $(\mathrm{M}=3,28 ; \mathrm{SD}=0,56)$, что указывает на приверженность обучению, развитию навыков, стремлению внести свой вклад в совершенствование этого мира и будущее намерение голосовать.

Относительно активного гражданского поведения необходимо отметить низкий интерес среди молодежи к такой политической активности, как членство в политической партии или участие в выборах ( $\mathrm{M}=2,27 ; \mathrm{SD}=0,86)$. В то же время, «личная активность» достаточно высокая $(\mathrm{M}=3,30$; $\mathrm{SD}=0,48)$, что демонстрирует высокую заботу о своем здоровье, своих талантах, независимость в решении проблем и стремление к финансовой независимости.

Уровень социальной активности среди молодежи достаточно низкий $(\mathrm{M}=2,31 ; \mathrm{SD}=0,64)$ - она не очень заинтересована в активности, связанной с развитием общества, например, с привнесением своего вклада в школьное сообщество или социальное благополучие. Наиболее низкими были результаты по шкале активности ради социальных изменений $(\mathrm{M}=1,82 ; \mathrm{SD}=0,59)$, которая выявила, что респонденты практически не принимают участие в акциях протеста ради изменений.

(C) Bondarevska Iryna, Mykhailenko Viktoriia DOI (article): https://doi.org/10.32626/2227-6246.2019-46.40-58 
В целом, наблюдается высокое пассивное и полуактивное гражданское поведение и низкое активное гражданское поведение, что говорит о присутствии потенциала и общем нежелании принимать участие в активных изменениях.

Важно отметить, что в Украине, в отличие от других стран, в которых проводились исследования по данной методике, нет гендерных различий ни по пассивному, ни по полуактивному, ни по активному гражданскому поведению. То есть, в Украине нет значительных отличий в гражданском поведении между девушками и юношами. В то же время, были выявлены отличия между гражданским поведением молодежи, живущей в городе и пгт, а также были выявлены некоторые различия в поведении в зависимости от возраста.

Рассмотрим особенности гражданского поведения в зависимости от места проживания (город, пгт). Проведение статистической процедуры ANOVA позволило выявить некоторые различия в гражданском поведении между жителями города и пгт. У подростков, живущих в пгт, более высокое полуактивное гражданское поведение, чем у подростков, живущих в городе. В то же время, между подростками, живущими в городе и пгт, различий по пассивному гражданскому поведению, то есть по национальной идентичности и патриотизму, выявлено не было.

Статистически значимые различия между подростками, живущими в городе и пгт, были выявлены также по следующим субшкалам гражданского поведения: «гражданская сила», «социальная активность» и «активность ради изменений». У подростков, живущих в городе, более высокая «социальная активность», включая вклад в школьное сообщество и благополучие других, по сравнению с подростками, живущими в пгт, хотя в обоих случаях баллы по этим субшкалам не достигали уровня «скорее да, чем нет». Следовательно, молодежь в общем не очень социально активна.

По сравнению с подростками из города, подростки из пгт более открыты для обучения и развития гражданской силы. (c) Bondarevska Iryna, Mykhailenko Viktoriia

DOI (article): https://doi.org/10.32626/2227-6246.2019-46.40-58 
Они проявляют желание внести вклад в улучшение этого мира и имеют намерение голосовать в будущем. И в городе, и в пгт баллы по данной субшкале выше значения «скорее да, чем нет». Также молодежь в пгт проявляет более высокую готовность принимать участие в акциях протеста ради изменений, но в обоих случаях баллы колебались между «скорее нет, чем да» и «определенно нет», указывая на то, что протестная готовность среди молодежи достаточно низкая.

Перейдем к рассмотрению зависимости гражданского поведения от возраста. Было выявлено несколько статистически значимых различий в гражданском поведении в зависимости от возраста респондентов, среди них одна шкала и две субшкалы. Пассивное гражданское поведение наиболее высокое в 11 лет, снижается в 14 лет и снова повышается в 18 лет, оставаясь достаточно высоким во всех возрастах. «Патриотизм» наиболее высокий в 11 лет, снижается в 14 лет и снова повышается в 18 лет. В то же время, во всех возрастах баллы по патриотизму не достигают уровня «скорее да, чем нет». «Законопослушность» наиболее высокая в 11 лет, снижается в 14 лет и снова повышается в 18 лет, оставаясь достаточно высокой во всех возрастных группах. Такие тенденции можно объяснить гражданской осознанностью в возрасте 18 лет и влиянием патриотического образования в возрасте 11 лет.

Подводя итоги данного исследования, связанного с гражданским поведением молодежи, следует отметить, что массовые протесты в городах, как правило, спровоцированы экстраординарными инцидентами, такими как чрезвычайная жестокость со стороны представителей властей, отсутствие минимальных условий, необходимых для жизни, чрезвычайное загрязнение и т. п. В других случаях граждане, как правило, пытаются адаптироваться к ситуации.

В современном мире информационных технологий сложно переоценить роль ледиа в развитии гражданской активности. Дж. Т. Джост с коллегами (Jost et al., 2018), проанализировав протестные движения в США, Испании, Турции

(C) Bondarevska Iryna, Mykhailenko Viktoriia DOI (article): https://doi.org/10.32626/2227-6246.2019-46.40-58 
и Украине, отмечают, что: 1) платформы социальных медиа способствуют обмену информацией, необходимой для координирования акций протеста, такой как новости о транспорте, забастовках, присутствии полиции, насилии, медицинском обслуживании и юридической поддержке; 2) платформы социальных медиа способствуют обмену эмоциональным и мотивационным контентом в поддержку или противодействие акциям протеста, включая сообщения, содержащие гнев, социальную идентификацию, эффективность группы, лишения, заботу о справедливости, правосудии, а также идеологические темы; 3) структурные характеристики онлайновых социальных сетей могут отличаться. Будучи функциями политической идеологии, они связаны с информационным воздействием и успехом или неудачей организации протестов. Использование социальных медиа было связано с распространением социальных протестов во многих городах по всему миру, включая Киев, Москву, Стамбул, Анкару, Каир, Триполи, Афины, Мадрид, Нью-Йорк, Лос-Анджелес, Гонконг.

Для организаторов протестных движений социальные медиа являются эффективным средством распространения информации о планировании мероприятий и политической ситуации. С другой стороны, использование социальных медиа дает возможность властям выявить и подавить протестную активность. Таким образом, технологическое взаимодействие между диссидентами и защитниками существующих режимов навряд ли когда-нибудь исчезнет (Jost et al., 2018).

Использование социальных медиа в значительной степени ускорило процессы, которые раньше проходили гораздо медленнее. Эффекты социальных медиа особенно заметны в закрытых авторитарных обществах, поскольку онлайн-общение создало возможности для оценивания общественного мнения, которых раньше не хватало гражданам (McGarty et al., 2013). Кроме этого, онлайновые технологии способствовали возникновению качественно новых форм политического участия (Jost et al., 2018).

(c) Bondarevska Iryna, Mykhailenko Viktoriia

DOI (article): https://doi.org/10.32626/2227-6246.2019-46.40-58 
С точки зрения анализа затрат и выгод, использование социальных медиа может повлиять на политическое поведение посредством изменения качества и / или количества информации, которая доходит до граждан. Например, социальные медиа могут повлиять на решение принимать участие в акциях протеста, меняя знания о затратах и выгодах такого участия. Социальные медиа распространяют информацию о том, когда, где и будут ли проходить акции протеста, а также своевременную информацию о забастовках, присутствии полиции и насилии. В то же время, информация, распространяемая через социальные медиа, может и снижать участие в акциях протеста, показывая высокие затраты такого участия, например, насилие со стороны полиции (Jost et al., 2018).

Дж. А. Тукер с коллегами (Tucker et al., 2014) проанализировали роль социальных медиа в массовых протестах 2014 года в Украине. Результаты показали, что социальные медиа, особенно Фейсбук, способствовали организации Евромайдана. Использование социальных медиа также позволяет следить за важными политическими изменениями во время кризиса. Использование Твиттера в Украине начиналось на очень низком уровне, но при каждой новой волне протестной активности количество аккаунтов существенно увеличивалось. Вероятно, многие украинцы присоединились к Твиттеру, чтобы следить за событиями Евромайдана. Опрос протестующих, проведенный О. Онуч (Onuch, 2014), показал, что $5 \%$ респондентов узнали о протестах из студенческой группы в Фейсбуке, $40 \%$ указали на то, что их участие в протестах поощряли в Фейсбуке друзья или члены семьи.

Дж. Т. Джост с коллегами (Jost et al., 2018) отмечают важность общей социальной идентичности в протестных акциях, принимая во внимание то, что каждый индивид относится к нескольким группам, основанным на гендере, расе, религии, идеологии, профессии, статусе отношений и т. д. Некоторые социальные идентичности могут быть не выраже-

(c) Bondarevska Iryna, Mykhailenko Viktoriia DOI (article): https://doi.org/10.32626/2227-6246.2019-46.40-58 
ны, но события-триггеры или изменения в окружении трансформируют латентную форму идентичности в чрезвычайно выраженную (Klandermans, 2014). Как правило, с увеличением выраженности социальной идентичности растет вероятность принять участие в коллективных акциях от имени этой социальной группы, а также участие в коллективных акциях увеличивает выраженность общей социальной идентичности с группой, на чьи недовольства направлены коллективные действия (Jost et al., 2018).

\section{Выводы и перспективы дальнейших исследований}

Развитие социально активного гражданского общества должно стать целью начиная со школы. Отсутствие активности и страх протестов среди граждан могут провоцировать неприемлемое поведение властей по причине отсутствия гражданского контроля. Поэтому развитие навыков, усиливающих гражданскую активность, связанную с противостоянием противозаконным действиям властей, должно стать частью гражданского образования.

Б. Кшивош-Рынкевич и А. Залевска (Krzywosz-Rynkiewicz \& Zalewska, 2015) приходят к выводу, что современный человек не ограничен одним контекстом, а живет в разных местах в одно и то же время, то есть живет, работает, отдыхает в разных регионах, культурах и странах. В информационном мире граждане могут быть членами национальных, локальных, государственных, этнических, глобальных сообществ. Поэтому гражданственность стоит рассматривать с разных сторон. В то же время, определение гражданственности через гражданское поведение выглядит наиболее универсальным. Такой подход способствует лучшему пониманию действий и их мотивов в сообществах. В настоящее время гражданственность связана не столько с национальной идентичностью, сколько с критическим анализом, принятием решений и мерами, принимаемыми сообществами для разрешения или предотвращения ежедневных проблем.

(c) Bondarevska Iryna, Mykhailenko Viktoriia

DOI (article): https://doi.org/10.32626/2227-6246.2019-46.40-58 
Социальные медиа играют не последнюю роль в формировании гражданского поведения во всем мире, распространяя информацию с невероятной скоростью и практически без цензуры. В этом контексте следует отметить важность навыков распознавания фейковых новостей и медиаграмотности, поскольку в периоды социальной, политической, экономической неопределенности особенно сложно отличить фейки от достоверной информации.

На наш взгляд, гражданскую активность как возможность повлиять на политические процессы и решения можно рассматривать как один из механизмов регулирования доверия к правительству и государственным институтам среди граждан. В Украине проблема доверия к правительству и государственным институтам давно связана с государственной безопасностью и территориальной целостностью государства. Нынешнюю политическую ситуацию в Украине частично можно объяснить кризисом доверия к власти. Таким образом, изучение гражданской активности как фактора политического доверия может в дальнейшем быть перспективным направлением исследования.

\section{References}

Bondarevska, I., Krzywosz-Rynkiewicz, B., \& Bondar, E. (2017). Young people's citizenship activity in times of war threat: Case of Ukraine. Citizenship Teaching and Learning, 12 (2), 189-206.

Eliasz, A. (2002). Psychologia ekologiczna [Ecological psychology]. In J. Strelau (Ed.). Psychologia (pp. 405-440). Gdańsk : GWP, Podręcznik akademicki [in Polish].

Herbst, J. (2005). Oblicza spoleczeństwa obywatelskiego [Faces of civil society]. Warszawa : FRSO [in Polish].

Jost, J. T., Barbera, P., Bonneau, R., Langer, M., Metzger, M., Nagler, J., Sterling, J., \& Tucker, J. A. (2018). How social media facilitates political protests: Information, motivation, and social networks. $A d$ vances in Political Psychology, 39 (1), 85-118.

Klandermans, P. G. (2014). Identity politics and politicized identities: Identity processes and the dynamics of protest. Political Psychology, 35 , p. 1-22.

(C) Bondarevska Iryna, Mykhailenko Viktoriia

DOI (article): https://doi.org/10.32626/2227-6246.2019-46.40-58 
Krzywosz-Rynkiewicz, B., \& Zalewska, A. M. (2015). Contemporary contexts and trends in citizenship studies. In A. Skarzauskiene (Ed.). Social technologies and collective intelligence (pp. 102-110). Vilnius : JSC «Vitae Litera», Mykolas Romeris University.

Lewicka, M. (2004). Kup pan książkę... Mechanizmy aktywności obywatelskiej Polaków [Buy a book... Mechanisms of civil activity of Poles]. Studia Psychologiczne, 42 (4), 65-82 [in Polish].

McGarty, C., Thomas, E. F., Lala, G., Smith, L. G., \& Bliuc, A. M. (2003). New technologies, new identities, and the growth of mass opposition in the Arab Spring. Political Psychology, 35 (6), 725-740.

Melosik, Z. (1998). Obywatelstwo, czas (historia), przestrzeń (geografia) [Citizenship, time (history), space (geography)]. In Z. Melosik i K. Przyszczypkowski (Ed.). Wychowanie obywatelskie. Studium teoretyczne, porównawcze i empiryczne. Poznań-Toruń : Edytor [in Polish].

Onuch, O. (2014, January 2). Social networks and social media in Ukrainian «Euromaidan» protests. Washington Post. Retrieved from https:// www.washingtonpost.com/news/monkey-cage/wp/2014/01/02/social-networks-and-social-media-in-ukrainian-euromaidan-protests-2/

Theiss-Morse, E. (1993). Conceptualizations of good citizenship and political participation. Political Behaviour, 15, 355-380.

Torney-Purta, J., Barber, C. H., \& Richardson, W. K. (2004). Trust in Government-Related Institutions and Political Engagement among Adolescents in Six Countries. Acta Politica, 39, p. 380-406.

Tucker, J. A., Metzger, M. M., Penfold-Brown, D., Bonneau, R., Jost, J. T., \& Nagler, J. (2014). Protest in the age of social media: Technology and Ukraine's \#EuroMaidan. Carnegie Reporter, 7 (4), p. 8-19.

Zalewska, A. M., \& Krzywosz-Rynkiewicz, B. (2011). Psychologiczne portrety mlodych obywateli [Psychological portraits of young citizens]. Warszawa : Wydawnictwo SWPS Academica [in Polish].

\section{Бондаревская Ирина, Михайленко Виктория. Гражданская активность: роль социальных медиа}

\section{АННОТАЦИЯ}

В статье представлены теоретические подходы к рассмотрению гражданской активности, а также типология гражданской активности, разработанная Б. Кшивош-Рынкевич и А. Залевской. Рассмотрена роль социальных медиа в развитии и распространении гражданской активности. Задачи статьи: 1) теоретический обзор исследований гражданской активности и роли социальных медиа в развитии и распространении гражданской активности; 2) анализ результатов эмпирического (C) Bondarevska Iryna, Mykhailenko Viktoriia

DOI (article): https://doi.org/10.32626/2227-6246.2019-46.40-58 http://journals.uran.ua/index.php/2227-6246 
DOI: https://doi.org/10.32626/2227-6246.2019-46

исследования гражданской активности молодежи. Для изучения особенностей гражданской активности подростков было проведено эмпирическое исследование в Кривом Роге и Софиевке с использованием Опросника гражданского поведения в качестве метода исследования. Каждая из трех шкал (активное, полуактивное и пассивное гражданское поведение) содержит субшкалы: активное гражданское поведение - «политическая активность", "активность ради изменений», "социальная активность», "личная активность»; полуактивное гражданское поведение - «законопослушность», "голосование», "общественное благо» и «честная работа»; пассивное гражданское поведение - «национальная идентичность» и "патриотизм». В исследовании принял участие 371 респондент. Результаты исследования показали высокое пассивное и полуактивное гражданское поведение и низкое активное гражданское поведение, что говорит о присутствии потенциала и общем нежелании принимать участие в активных изменениях. Показано, что в Украине, в отличие от других стран, в которых проводились исследования по данной методике, нет гендерных различий ни по пассивному, ни по полуактивному, ни по активному гражданскому поведению. В то же время, были выявлены отличия между гражданским поведением молодежи, живущей в городе и пгт, а также были выявлены некоторые различия в гражданском поведении в зависимости от возраста. Сделан вывод о том, что гражданскую активность как возможность повлиять на политические прочессы и решения можно рассматривать как один из механизмов регулирования доверия к правительству и государственным институтам среди граждан. Отмечена важность навыков распознания фейковых новостей и медиаграмотности, поскольку в периоды социальной, политической, экономической неопределенности особенно сложно отличить фейки от достоверной информации.

Ключевые слова: гражданская активность, типы гражданской активности, гражданская активность подростков, социальные медиа, акции протеста.

Бондаревська Ірина, Михайленко Вікторія. Громадянська активність: роль сочіальних медіа

\section{АНОТАЦІЯ}

У статті представлено теоретичні підходи до розгляду громадянської активності, а також типологію громадянської активності, розробле-

(C) Bondarevska Iryna, Mykhailenko Viktoriia DOI (article): https://doi.org/10.32626/2227-6246.2019-46.40-58 
ну Б. Киивош-Ринкевич і А. Залевскою. Розглянуто роль соціальних медіа в розвитку і поширенні громадянської активності. Завдання статmі: 1) теоретичний огляд досліджень громадянської активності й ролі соціальних медіа в розвитку і поширенні громадянської активності; 2) аналіз результатів емпіричного дослідження громадянської активності молоді. Для вивчення особливостей громадянської активності підлітків було проведено емпіричне дослідження у Кривому Розі й Софіївці з використанням Опитувальника громадянської поведінки в якості методу дослідження. Кожна з трьох шкал (активна, напівактивна і пасивна громадянська поведінка) містить субшкали: активна громадянська поведінка - «політична активність», "активність заради змін», "сочіальна активність», "особиста активність»; напівактивна громадянська поведінка - «законослухняність", "голосування», "суспільне благо» та "чесна робота»; пасивна громадянська поведінка - «національна ідентичність» $i$ «патріотизм». У дослідженні прийняв участь 371 респондент. Результати дослідження показали високу пасивну і напівактивну громадянську поведінку та низьку активну громадянську поведінку, що говорить про наявність потенціалу й загального небажання приймати участь в активних змінах. Показано, що в Україні, на відміну від інших країн, у яких проводилося дослідження за цією методикою, немає ґендерних відмінностей ні за пасивною, ні за напівактивною, ні за активною громадянською поведінкою. Водночас було виявлено відмінності між громадянською поведінкою молоді, яка проживає у місті та смт, а також було виявлено деякі відмінності в громадянській поведінці залежно від віку. Зроблено висновок про те, що громадянську активність, як можливість вплинути на політичні прочеси і рішення, можна розглядати як один із механізмів регулювання довіри до уряду та державних інститутів серед громадян. Відзначено важливість навичок розпізнавання фейкових новин і медіаграмотності, оскільки в періоди сочіальної, політичної, економічної невизначеності особливо складно відрізнити фейки від достовірної інформації.

Ключові слова: громадянська активність, типи громадянської активності, громадянська активність підлітків, сочіальні медіа, акції проmecmy.

Original manuscript received September 17, 2019 Revised manuscript accepted October 20, 2019

(C) Bondarevska Iryna, Mykhailenko Viktoriia

DOI (article): https://doi.org/10.32626/2227-6246.2019-46.40-58 